"This document is the Accepted Manuscript version of a Published Work that appeared in final form in Analytical Chemistry, () 2016 American Chemical Society after peer review and technical editing by publisher. To access the final edited and published work see Saran, R., \& Liu, J. (2016). A Silver DNAzyme. Analytical Chemistry, 88(7), 4014-4020. http://dx.doi.org/10.1021/acs.analchem.6b00327

\title{
A Silver DNAzyme
}

\author{
Runjhun Saran and Juewen Liu*
}

Department of Chemistry, Waterloo Institute for Nanotechnology, University of Waterloo

Waterloo, Ontario, Canada, N2L 3G1.

Phone: 519-888-4567, extension 38919

Email: liujw@uwaterloo.ca 


\begin{abstract}
Silver is a very common heavy metal, and its detection is of significant analytical importance. DNAzymes are DNA-based catalysts; they typically recruit divalent and trivalent metal ions for catalysis. Herein, we report a silver-specific RNA-cleaving DNAzyme named Ag10c obtained after six rounds of in vitro selection. Ag10c displays a catalytic rate of $0.41 \mathrm{~min}^{-1}$ with $10 \mu \mathrm{M} \mathrm{Ag}^{+}$ at pH 7.5 with $200 \mathrm{mM} \mathrm{NaNO}$, while its activity is completely inhibited with the same concentration of $\mathrm{NaCl}$. Ag10c is highly specific for $\mathrm{Ag}^{+}$among all the tested metals. A catalytic beacon biosensor is designed by labeling a fluorophore and a quencher on the DNAzyme. Fluorescence enhancement is observed in the presence of $\mathrm{Ag}^{+}$with a detection limit of $24.9 \mathrm{nM}$ $\mathrm{Ag}^{+}$. The sensor shows a similar analytical performance in Lake Huron water. This is the first monovalent transition metal dependent RNA-cleaving DNAzyme. Apart from its biosensor application, this study strengthens the idea of exploring beyond the traditional understanding of multivalent ion dependent DNAzyme catalysis.
\end{abstract}




\section{Introduction}

Metallic silver, its alloys and compounds have been used in jewellery, solar cells, antimicrobial agents, dental amalgams, photography, electronic components, glass coatings and catalysis, among other applications. ${ }^{1}$ Such widespread usage has led to environmental contamination. Silver is a heavy metal and poses a health threat as it tends to bioaccumulate, causing damages to the skin, eyes, liver, kidneys and intestinal tracts. ${ }^{2}$ While silver can be measured by instrumentation methods such as ICP-MS, it is also important to develop biosensors for on-site detection, which may also help recover this valuable metal. ${ }^{3,4}$

Over the past two decades, DNA has emerged as a highly versatile platform for metal sensing based on either metal/nucleobase binding interactions or metal-assisted DNAzyme catalysis. ${ }^{5-10}$ RNA-cleaving DNAzymes are particularly interesting since they can achieve extremely high metal sensitivity and are versatile in biosensor design. ${ }^{11,12}$ DNAzymes are DNAbased catalysts isolated using in vitro selection. ${ }^{13}$ They often recruit divalent metals for catalysis, and in vitro selections can be intentionally performed to evolve DNAzymes that work only in the presence of specific metals. ${ }^{14}$ Many divalent metals including $\mathrm{Pb}^{2+},{ }^{15} \mathrm{Zn}^{2+},{ }^{16} \mathrm{Cu}^{2+},{ }^{17}, 18 \mathrm{UO}_{2}{ }^{2+},{ }^{19}$ $\mathrm{Cd}^{2+},{ }^{20}$ and $\mathrm{Hg}^{2+}$ have been detected using DNAzymes. ${ }^{21}$ Recently, important advancements have been made on trivalent metals as well; we isolated and a few lanthanide-dependent DNAzymes. ${ }^{12}$, $22-24$

The perception of multivalent metals requirement was relaxed by the recent discovery of DNAzymes that use only monovalent $\mathrm{Na}^{+} \cdot{ }^{25-27}$ For example, the Lu group reported a DNAzyme with a rate of $\sim 0.1 \mathrm{~min}^{-1}$ using $\mathrm{Na}^{+}$as the sole metal. ${ }^{27}$ To reach such a high rate, however, 400 $\mathrm{mM} \mathrm{Na}{ }^{+}$is needed. The same $\mathrm{Na}^{+}$binding motif was also identified in another lanthanidedependent DNAzyme. ${ }^{24,28,29}$ We isolated a $\mathrm{Na}^{+}$-specific DNAzyme named EtNa, also requiring 
high $\mathrm{mM} \mathrm{Na}^{+}$in water but low $\mathrm{mM} \mathrm{Na}^{+}$in ethanol. ${ }^{30}$ It remains unclear whether it is possible to obtain DNAzymes that can work with nanomolar transition metals. If existing, these DNAzymes will be not only analytically useful, but can answer fundamental questions in bioinorganic DNA chemistry.

The most studied interaction between DNA and silver is the specific binding between the cytosine base and $\mathrm{Ag}^{+} .{ }^{31,32}$ This interaction was used to develop $\mathrm{Ag}^{+}$biosensors, ${ }^{33-35}$ and for making fluorescent silver nanoclusters. ${ }^{36,37}$ While DNAzymes have also been used for $\mathrm{Ag}^{+}$ detection, ${ }^{35}$ these sensors still rely on the capturing of $\mathrm{Ag}^{+}$by cysteine pairs, and $\mathrm{Ag}^{+}$does not participate in catalysis. Herein, we report the first $\mathrm{Ag}^{+}$-specific RNA-cleaving DNAzyme named Ag10c, and a highly sensitive and selective biosensor using this DNAzyme.

\section{Materials and Methods}

Chemicals. The in vitro selection and sensing related DNA samples were from Integrated DNA Technologies (Coralville, IA). The rest of the DNAs were from Eurofins (Huntsville, $\mathrm{AL}$ ). $\mathrm{AgNO}_{3}$ and other metal salts were from Sigma-Aldrich at the highest purity available. Sodium acetate, 2( $N$-morpholino) ethanesulfonic acid (MES), 3-( $N$-morpholino) propanesulfonic acid (MOPS), ethylenediaminetetraacetic acid (EDTA) disodium salt dihydrate, sodium chloride and ammonium acetate were from Mandel Scientific Inc. (Guelph, Ontario, Canada). Sso Fast EvaGreen supermix was from Bio-Rad. T4-DNA ligase, deoxynucleotide (dNTP) mix, Taq DNA polymerase with ThermoPol buffer and low molecular weight DNA ladder were from New England Biolabs.

In vitro selection. The method of in vitro selection was derived from our previous report with some minor modifications. ${ }^{24}$ In brief, the initial library was obtained by ligating Lib-FAM-N50 and Lib-rA (see Table S1 for DNA sequences). For each subsequent round, the library was 
produced by PCR. For each cleavage step, a freshly prepared $\mathrm{AgNO}_{3}$ solution was added to the DNA library in buffer A (50 mM MES, pH 6.0, $25 \mathrm{mM} \mathrm{NaNO}_{3}$ ) with 60 min incubation (final 10 $\left.\mu \mathrm{M} \mathrm{Ag}^{+}\right)$. After incubation, the library was mixed with $8 \mathrm{M}$ urea and purified by $10 \% \mathrm{dPAGE}$ (denaturing polyacrylamide gel electrophoresis). The position corresponding to the cleavage product was excised from the gel, the DNA was extracted by crushing and soaking the gel, and the sample was further desalted with a Sep-Pak C18 column (Waters). After drying in an Eppendorf Vacufuge at $30{ }^{\circ} \mathrm{C}$ overnight, the dried DNA was re-suspended in $60 \mu \mathrm{L}$ of $5 \mathrm{mM}$ HEPES buffer ( $\mathrm{pH}$ 7.5). A small fraction of this DNA was amplified by two rounds of PCR (PCR1 and PCR2) using previously described thermoscycling conditions. ${ }^{24}$

Deep sequencing. To prepare sample for deep sequencing, the round 6 library was subjected to PCR1 as explained above. The full-length library generated from this step was subjected to another PCR reaction so that the Illumina sequencing technology can be used. The forward primer (P701) and the reverse primer (P501) each containing a unique index sequence were used (see Table S1). The PCR product was purified with $2 \%$ agarose gel and extracted using a gel extraction kit (IBI Scientific). The extracted DNA was eluted in $25 \mu \mathrm{L}$ Milli-Q water and the concentration was quantified using a NanoDrop spectrophotometer to be $9 \mathrm{ng} / \mu \mathrm{L}$, and the sequencing was performed at McMaster University.

Activity assays. For cleavage activity assays, the DNAzyme complex were prepared by annealing the FAM-labeled substrate $(10 \mu \mathrm{M})$ and enzyme $(30 \mu \mathrm{M})$ in buffer A. Other $\mathrm{pH}$ and salt concentrations were also tested. Assays were performed with a final concentration of $0.4 \mu \mathrm{M}$ of the FAM-labeled substrate and $1.2 \mu \mathrm{M}$ of the enzyme. A final of $0.05-200 \mu \mathrm{M} \mathrm{Ag}^{+}$was added to initiate the cleavage reaction. The products were separated on a denaturing PAGE gel and analyzed using a Bio-Rad Chemi-Doc MP imaging system. For determining the rate of cleavage, the gel 
band intensities were quantified and the data obtained were fitted according to the first-order rate equation $Y_{t}=Y_{o}+a\left(1-e^{-k x}\right)$, where $Y_{t}$ and $Y_{o}$ are the cleavage fractions at a given reaction time $t$ and time zero, respectively, and $k$ is the rate constant.

Fluorescence-based $\mathbf{A g}^{+}$sensing. Sensor signaling kinetics were measured in 96-well plates using a microplate reader (SpectraMax M3). The sensing complex was formed by annealing 5'-FAMSub $(10 \mu \mathrm{M})$ and the quencher-labeled enzyme (Ag10c-Q, $20 \mu \mathrm{M})$ in buffer (50 mM MOPS, pH 7.0 with $25 \mathrm{mM} \mathrm{NaNO}_{3}$ ). Finally, $0.5 \mu \mathrm{L}$ of the above annealed sensor was diluted with $97.5 \mu \mathrm{L}$ buffer (50 mM MOPS pH 7.5, $200 \mathrm{mM} \mathrm{NaNO}_{3}$ ) in the plate. A $2 \mu \mathrm{L}$ amount of target ions was added to initiate the cleavage reaction. Samples were continuously monitored for at least $30 \mathrm{~min}$ with $20 \mathrm{sec}$ intervals.

\section{Results and Discussion}

In vitro selection using $\mathbf{A g}^{+}$. In vitro selection refers to the isolation of a subset of DNA sequences with a desired function from a large library. ${ }^{13}$ Our goal here was to obtain RNA-cleaving DNAzymes that work specifically with $\mathrm{Ag}^{+}$. The scheme of selection is shown in Figure 1A. Our DNA library contains 50 random nucleotides (see Figure 1B for the library sequence), and a single RNA linkage (rA, denotes for ribo-adenine). Since RNA is much more susceptible to cleavage, ${ }^{38}$ this is an artificially introduced cleavage site. The initial library contained $\sim 10^{13}$ random DNA sequences. The role of metal ions in RNA cleavage has been extensively studied, ${ }^{39,40}$ and we hoped that certain DNA sequences can utilize $\mathrm{Ag}^{+}$for this reaction. If this hypothesis is true, a fraction of the library (originally length $=119$ nucleotide (nt)) might be cleaved at this RNA junction by $\mathrm{Ag}^{+}$and thus became shorter by $28 \mathrm{nt}$. We harvested the cleaved fragment (91 nt) using denaturing 
gel electrophoresis, and amplified it by two rounds of PCR to re-generate the full-length library for the next round of selection. PCR1 brings the library back to the original length, and PCR2 introduces the FAM fluorophore and rA.

Throughout the selection, the $\mathrm{Ag}^{+}$concentration was maintained at $10 \mu \mathrm{M}$ with $1 \mathrm{~h}$ incubation time. The FAM label allowed us to quantify the cleavage yield at each round, and a gradual increase was observed (Figure 1C). However, this increase was quite slow. At round 6, only $\sim 8 \%$ of the library was cleaved. This indicates that $\mathrm{Ag}^{+}$-dependent sequences did not dominate the library, and non-specific cleavage was competing. The gradually increased cleavage however still suggested a small population that might depend on $\mathrm{Ag}^{+}$. To identify this population, instead of the conventional cloning method, we resorted to deep sequencing at round 6; a total of 54,961 sequences were obtained.

A
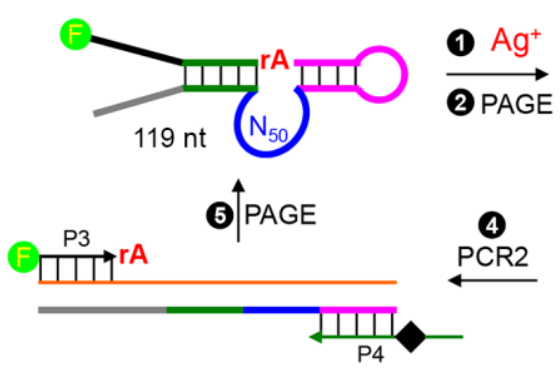

B

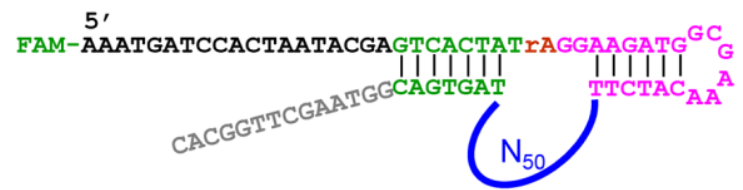

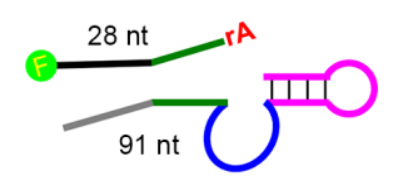
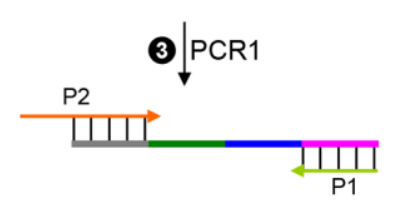

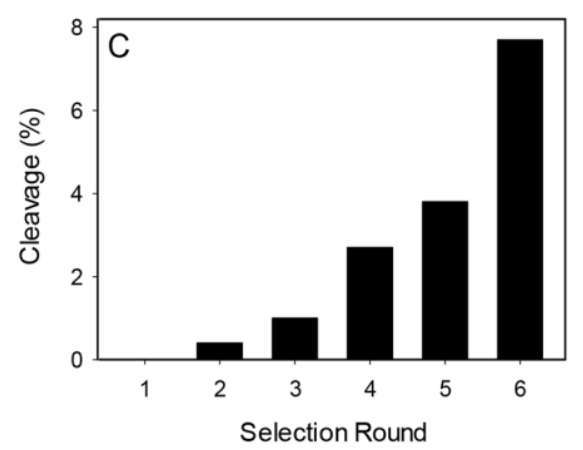

Figure 1. (A) The schematic representation of our in vitro selection with five steps. $\mathrm{Ag}^{+}$is used to induce cleavage. Two PCR steps are used to convert the cleaved sequence back to the original full length. The P4 primer has a polymer spacer (denoted by the black diamond) to stop the PCR extension, yielding two strands of unequal lengths. The shorter strand is harvested in step 5 for the next round of selection. (B) The sequence of the library for our in vitro selection with 50 random 
nucleotides $\left(\mathrm{N}_{50}\right)$. The cleavage site is at the rAG junction. (C) Progress of our selection. At each round, $10 \mu \mathrm{M} \mathrm{Ag}^{+}$with $1 \mathrm{~h}$ incubation was made in buffer A (50 mM MES, pH 6.0, $25 \mathrm{mM}$ $\left.\mathrm{NaNO}_{3}\right)$.

Sequence Analysis. Upon aligning the sequences, 874 families were obtained. The most populated first 200 families, accounting for $88.8 \%$ of all the sequences, were examined for their secondary structures using Mfold ${ }^{41}$ Interestingly, a few families accounting to $1.5 \%$ of the analyzed sequences belong to the Ce13d DNAzyme or its variants, which was previously selected in our lab. ${ }^{24,42}$ About $91 \%$ of the analyzed sequences contained a motif of TTCTCACA, which is a signature of another DNAzyme discovered in our lab, named EtNa. ${ }^{30} \mathrm{EtNa}$ is activated by $\mathrm{Na}^{+}$ alone and accelerated by ethanol, and this may explain the large population of $\mathrm{Ag}^{+}$-independent sequences. Only $7.5 \%$ of the analyzed sequences appeared novel, from which we engineered nineteen different trans-cleaving DNAzymes (Figure 2A). See Figure S1 for an example of converting the cis-cleaving Ag10 DNAzyme to its trans-cleaving form. The full-length transcleaving Ag10 DNAzyme is shown in Figure 3A. The enzyme strand binds the substrate using the two duplex regions, and the middle part is the catalytic core. In Figure 2A, the postulated catalytic cores are in boldface, and the rest of the sequences are the substrate binding arms (see table S1 for complete DNA sequences).

Each sequence in Figure 2A was individually tested by hybridizing with the FAM-labeled substrate in $10 \mu \mathrm{M} \mathrm{Ag}^{+}$(Figure 2B). Significant cleavage after $1 \mathrm{~h}$ was observed only for two sequences ( $\mathrm{Ag} 9$ and $\mathrm{Ag} 10)$. $\mathrm{Ag} 10$ (marked in red) produced the highest cleavage and was studied further. 


\begin{tabular}{|c|c|}
\hline Ag1 & 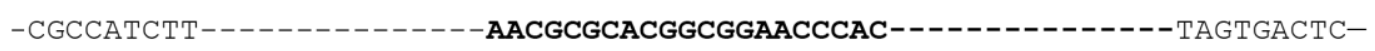 \\
\hline Ag2 & 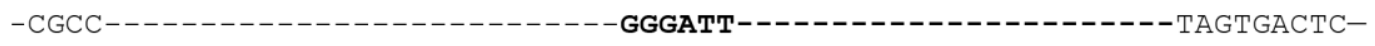 \\
\hline g3 & GCCATCTT--------------GGGGGGCGGAAGGGCTGCGC------n \\
\hline Ag 4 & CGCCAT--------------GCGGAACCCACCTACACGGATGGC--------------TAGTGACTC- \\
\hline Ag5 & CGCCAT--------------------GGAACACACCCGGGG---n----n \\
\hline Ag6 & 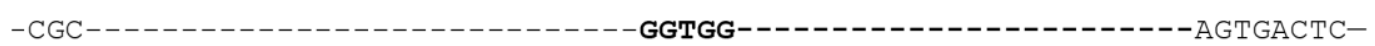 \\
\hline Ag7 & CGCCATC--CATAGCAGAGCGTCTAGAGATGTAAGTAAATCTTTTCTCAGCGAGACGAAATAGTGACTC- \\
\hline Ag8 & CGCCATCTT-------------GGCGGACTGGGTGGCTGTGG---------------TAGTG \\
\hline Ag9 & АTCTTTAGGCCTTAAACCCGTTGTAGGATTTGTAAGTCATTACTCTGAAGACGT-ATAGTG. \\
\hline 910 & СGCCATCTTTAGGTGATTTCCACGATAGAGAAACTATTATGCGGAAACAGGGCAGCGT-ATAGTG \\
\hline 11 & 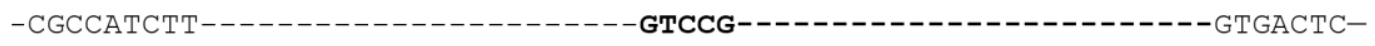 \\
\hline g12 & 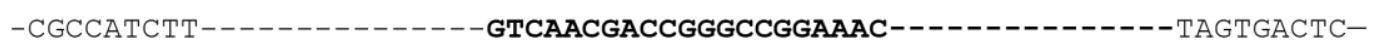 \\
\hline g13 & СGCCATCTT-----------GAGCATGAAGGCTCCATAAGTCGCGGG-------n----ATAGT \\
\hline 914 & CGCCATCTTTTAGAACTTAAATTCACGTAGCGCCAAGGGGTGATATGAGGCGACCGTGTATAGT \\
\hline Ag15 & CGCCATC---------------GCGGTTAATTGAGTCGCACCGAC---n \\
\hline g16 & 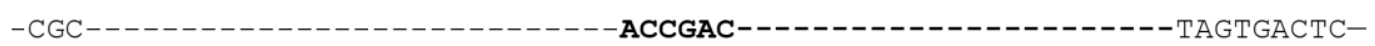 \\
\hline 917 & 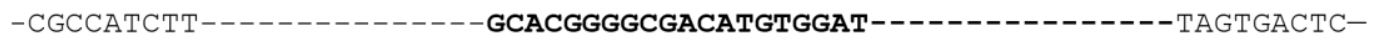 \\
\hline g18 & 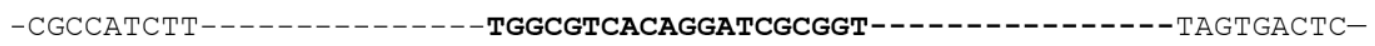 \\
\hline 919 & 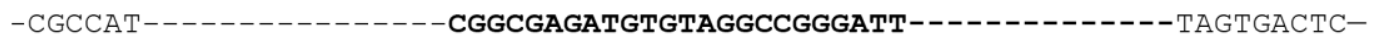 \\
\hline
\end{tabular}

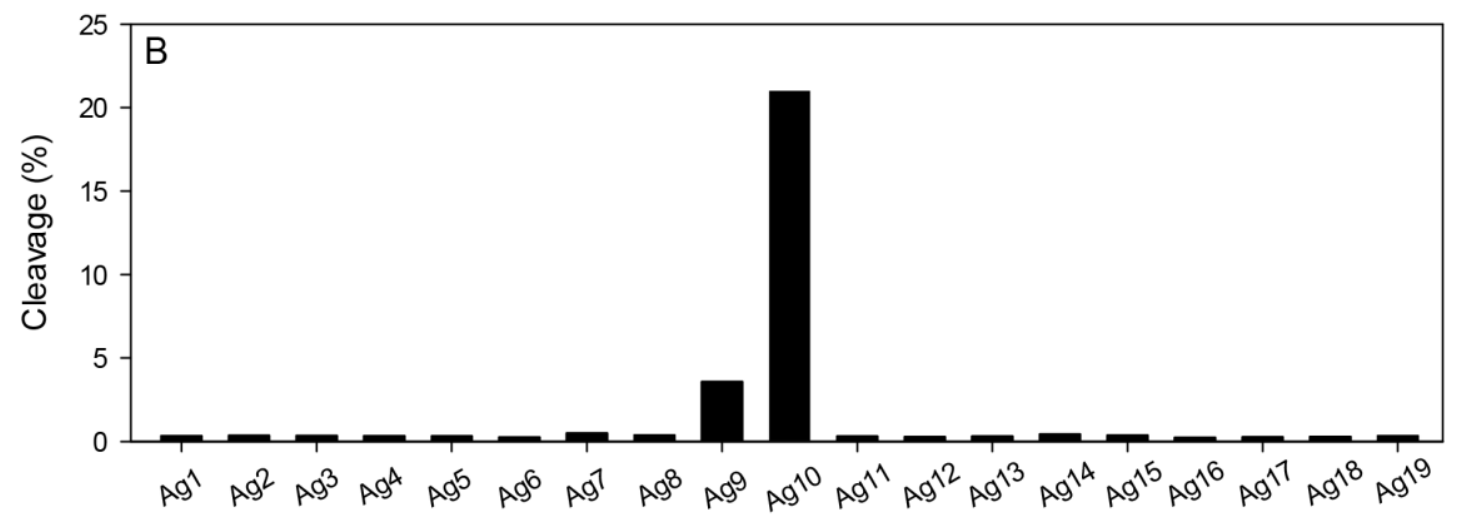

Figure 2. (A) The sequences of the 19 potential $\mathrm{Ag}^{+}$-dependent trans-cleaving DNAzymes from $5^{\prime}$ to $3^{\prime}$ with the hypothetic catalytic loop regions in bold. The catalytic loops are connected to the substrate binding arms. The copy number of each sequence from the sequencing results is also shown. The Ag10 sequence is in red. (B) Cleavage yield of the above sequences in buffer A with $10 \mu \mathrm{M} \mathrm{Ag}^{+}$for $1 \mathrm{~h}$. 
Based on the secondary structure of Ag10 (Figure 3A), we truncated the nucleotides in black, which appear to be redundant. This truncated DNAzyme is named Ag10c (Figure 3B), which retained a similar activity as the original Ag10 DNAzyme (Figure 3C). Ag10c has a hairpin, and two long unpaired bulges connecting this hairpin to the two substrate binding arms. Such a structure is typical of RNA-cleaving DNAzymes, ${ }^{19,24,27,30}$ and the hairpins usually play only a structural role. Metal binding is likely to take place in the large loop formed by the two unpaired bulges.

Since $\mathrm{Ag}^{+}$is known to stabilize cytosine-cytosine mismatches, ${ }^{31}$ and this might be a way for $\mathrm{Ag}^{+}$to exert an allosteric effect in promoting DNAzyme activity, ${ }^{35,43}$ From this secondary structure, however, we cannot identify potential $\mathrm{C}-\mathrm{Ag}^{+}-\mathrm{C}$ base pairs that can stabilize a stem-loop structure. ${ }^{43}$ There are only three cytosine nucleotides on one side of the catalytic loop, and two more in the hairpin loop. Therefore, the role of $\mathrm{Ag}^{+}$is likely to go beyond stabilization of simple DNAzyme secondary structures. We believe $\mathrm{Ag}^{+}$might directly participate in catalysis, and biochemical characterization of Ag10c to support this hypothesis will be a subject of future studies. Since Ag10c is shorter than Ag10c, it was used from this point on.
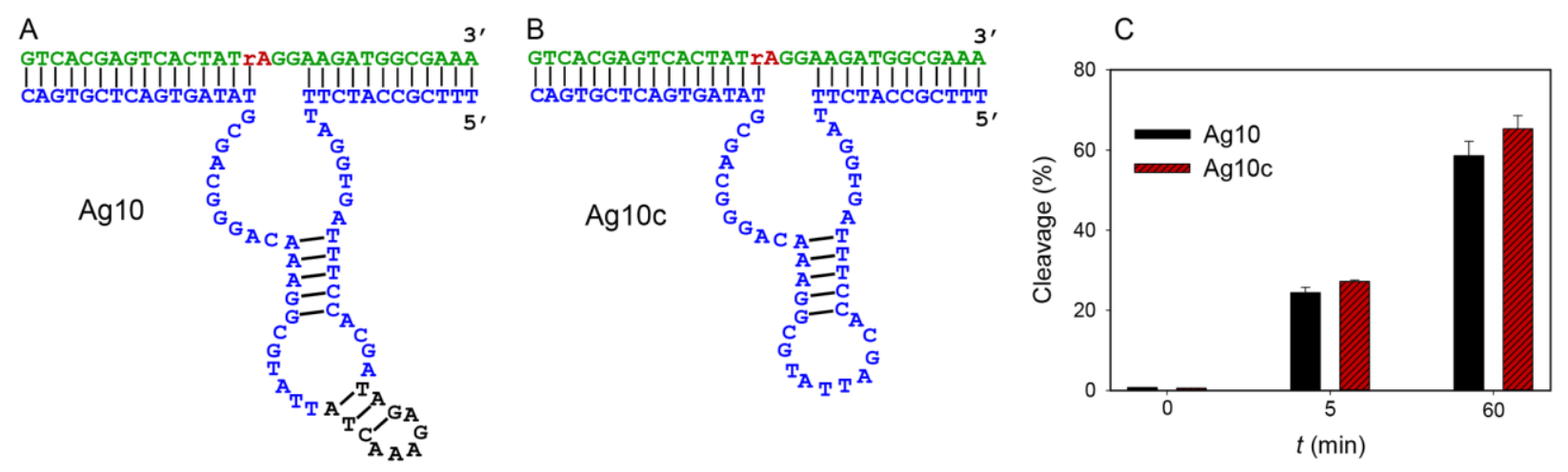

Figure 3. The secondary structures of (A) the Ag10 DNAzyme and (B) its truncated form Ag10c. 
The substrate strand is in green and the enzymes in blue/black. (C) The cleavage yields of the two DNAzymes with $10 \mu \mathrm{M} \mathrm{Ag}^{+}$at a few time points (buffer: $50 \mathrm{mM}$ MOPS, pH 7.0, $25 \mathrm{mM} \mathrm{NaNO}_{3}$ ).

Optimization of cleavage conditions. To identify an optimal condition for $\mathrm{Ag}^{+}$detection, we performed preliminary characterizations on $\mathrm{Ag} 10 \mathrm{c}$. We first studied the effect of $\mathrm{pH}$ (Figure 4A). The cleavage yields at two time points (5 and $60 \mathrm{~min}$ ) were measured, and higher $\mathrm{pH}$ produced higher cleavage yields up to $\mathrm{pH} 8$. Therefore, high $\mathrm{pH}$ is more favorable for the reaction, which might be related to the deprotonation of the $2^{\prime}-\mathrm{OH}$ of the RNA base, making it a better nucleophile. ${ }^{44}$ The solubility limit of $\mathrm{Ag}^{+}$is about $1 \mathrm{mM}$ at $\mathrm{pH} 9 .{ }^{45}$ Therefore, we were far below this limit in the above experiments, and $\mathrm{Ag}+$ precipitation was not a concern here.

Next, we tested various concentrations of $\mathrm{Ag}^{+}$at $\mathrm{pH} 7.0$ in $25 \mathrm{mM} \mathrm{NaNO}_{3}$ by measuring the cleavage yield at $5 \mathrm{~min}$. The yield was low below $1 \mu \mathrm{M} \mathrm{Ag}^{+}$, and it then rapidly increased (Figure 4B). The most optimal concentration was $10 \mu \mathrm{M} \mathrm{Ag}^{+}$. At even higher $\mathrm{Ag}^{+}$concentrations, inhibition was observed, which might be attributable to non-specific $\mathrm{Ag}^{+}$binding to DNA bases, inducing denaturation or misfolding of the DNAzyme.

Under an optimal condition of pH 7.5 with $200 \mathrm{mM} \mathrm{NaNO}_{3}$ and $10 \mu \mathrm{M} \mathrm{Ag}^{+}$, we measured the cleavage kinetics (Figure 4C). The kinetic profile was fitted to a first-order reaction with a rate constant of $0.41 \mathrm{~min}^{-1}$. This is a very fast rate considering $\mathrm{Ag}^{+}$is a monovalent metal ion and no divalent metals were added. For comparison, the recently reported $\mathrm{Na}^{+}$-specific DNAzyme has a rate of $0.11 \mathrm{~min}^{-1}$ with $400 \mathrm{mM} \mathrm{Na}^{+} .{ }^{14}$ This fast cleavage rate also suggests that $\mathrm{Ag}^{+}$might directly participate in catalysis. So far, no DNAzymes with $\mathrm{Na}^{+}$alone can achieve such a high rate. ${ }^{26,27,30}$ 

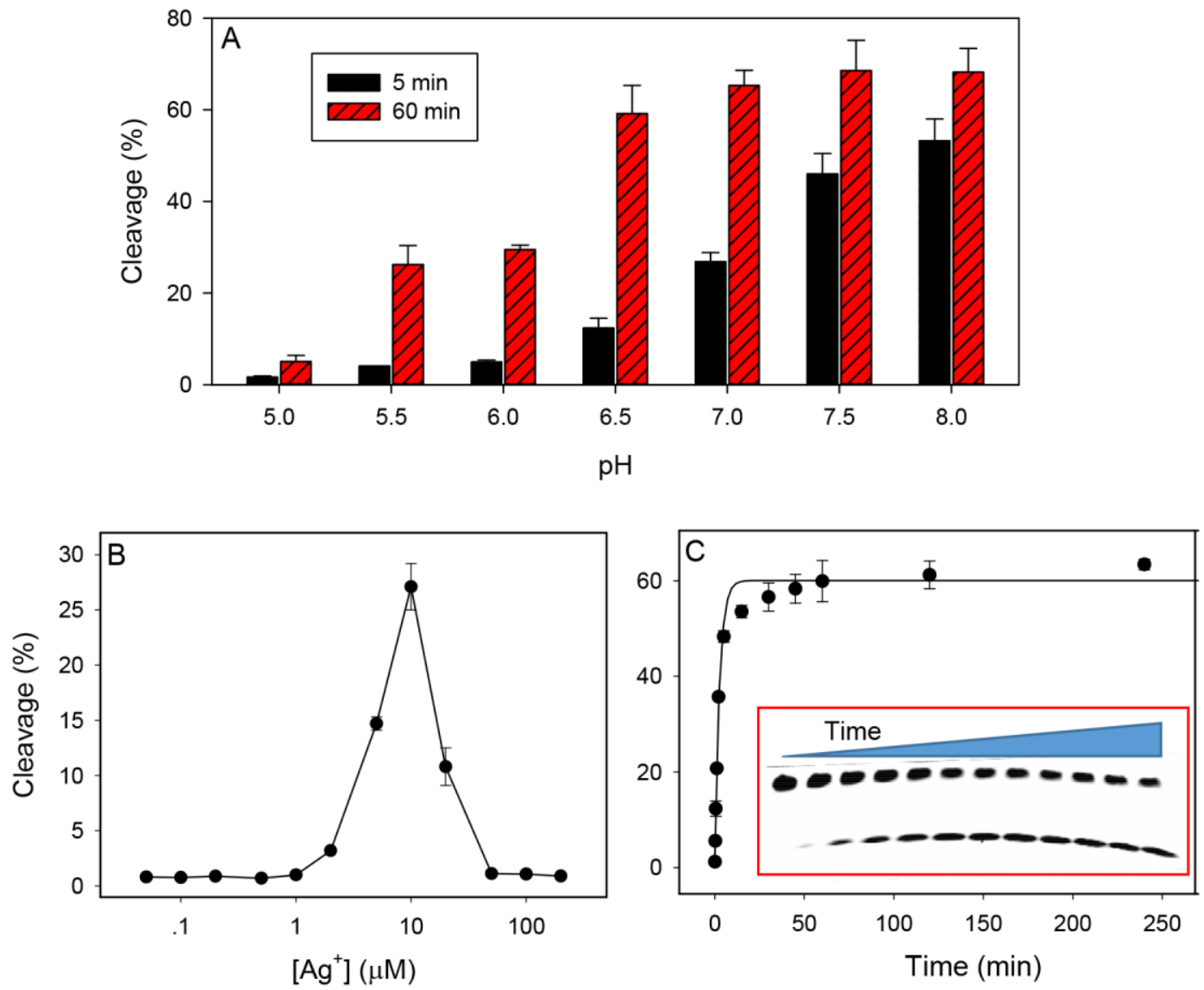

Figure 4. The cleavage yield of the Ag10c DNAzyme at (A) different pH with $25 \mathrm{mM} \mathrm{NaNO}_{3}$, (B) $\mathrm{pH} 7.0,50 \mathrm{mM}$ MOPS and $25 \mathrm{mM} \mathrm{NaNO}_{3}$ at various $\mathrm{Ag}^{+}$concentrations in 5 min. (C) Kinetics of Ag10c cleavage with $10 \mu \mathrm{M} \mathrm{Ag}^{+}$at $\mathrm{pH} 7.5$ with $200 \mathrm{mM} \mathrm{NaNO}_{3}$, yielding a rate of $0.41 \mathrm{~min}^{-1}$. Inset: a gel image at different time points $(0,0.16,0.5,1,2,5,15,30,45,60,120$ and $240 \mathrm{~min})$. The upper bands are the original substrate and the lower bands are the cleavage product.

Chloride inhibition proving $\mathbf{A g}^{+}$requirement. As this is the first case of DNAzyme catalysis using a monovalent transition metal ion, we performed the following experiment to confirm its $\mathrm{Ag}^{+}$requirement. The cleavage yield of $\mathrm{Ag} 10 \mathrm{c}$ was measured in the presence of increasing 
concentrations of $\mathrm{NaNO}_{3}$ or $\mathrm{NaCl}$ (Figure 5A). With $\mathrm{NaNO}_{3}$, the cleavage reached a similar value for all the conditions (red bars), while a strong inhibition effect of $\mathrm{NaCl}$ was observed when the $\mathrm{Cl}^{-}$was greater than $50 \mathrm{mM}$ (black bars). The cleavage went to the background level with more than $100 \mathrm{mM} \mathrm{NaCl}$. The solubility product $\left(k_{\mathrm{sp}}\right)$ of $\mathrm{AgCl}$ is $1.8 \times 10^{-10}$. Therefore, with $100 \mathrm{mM}$ $\mathrm{Cl}^{-}$, the free $\mathrm{Ag}^{+}$concentration is only $\sim 18 \mathrm{nM}$. As will be seen later, the DNAzyme cannot detect $\mathrm{Ag}^{+}$beyond this level. Since $\mathrm{NaNO}_{3}$ did not decrease the cleavage yield, the inhibition by $\mathrm{NaCl}$ cannot be attributed to the change in ionic strength. Taken together, the inhibition effect of $\mathrm{NaCl}$ is attributable to complex formation with $\mathrm{Ag}^{+}$or forming $\mathrm{AgCl}$ precipitation. This experiment provides a strong evidence that $\mathrm{Ag}^{+}$is critical for the activity of the DNAzyme.
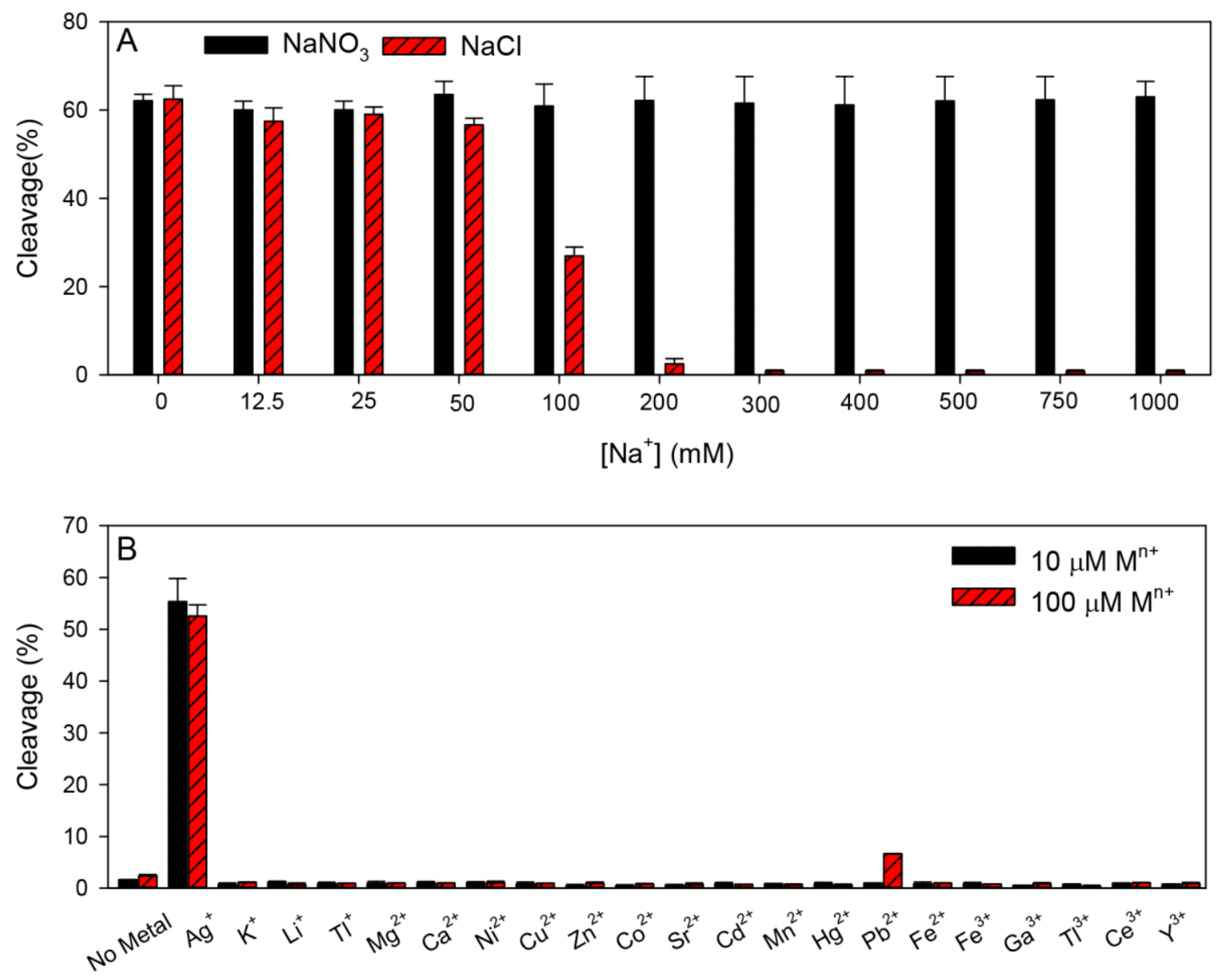
Figure 5. (A) The cleavage yield of $\mathrm{Ag} 10 \mathrm{c}$ in presence of $10 \mu \mathrm{M} \mathrm{Ag}^{+}$and various concentrations of $\mathrm{NaCl}$ or $\mathrm{NaNO}_{3}$. (B) Cleavage yield with $\mathrm{Ag}^{+}$as compared to $10 \mu \mathrm{M}$ and $100 \mu \mathrm{M}$ of 20 other metals. All the reactions were performed in $50 \mathrm{mM}$ MOPS, pH 7.0 for $1 \mathrm{~h}$. While $100 \mu \mathrm{M} \mathrm{Pb}^{2+}$ showed a modest cleavage, its rate is $>3000$-fold slower compared to the same concentration of $\mathrm{Ag}^{+}$

Ag10c is highly specific for $\mathbf{A g}^{+}$. Our in vitro selection was carried out with $\mathrm{Ag}^{+}$and no negative selections were performed. For $\mathrm{Ag}^{+}$sensing, metal specificity is also very important. We next tested Ag10c in the presence of $10 \mu \mathrm{M}$ and $100 \mu \mathrm{M}$ of 20 different metal ions (Figure 5B). Indeed, Ag10c is highly specific for $\mathrm{Ag}^{+}$and it has negligible or no activity in the presence of any other metal. Only $100 \mu \mathrm{M} \mathrm{Pb}^{2+}$ produced a very moderate cleavage of $\sim 8 \%$ after $1 \mathrm{~h}$. The interference by $\mathrm{Pb}^{2+}$ is commonly seen in the DNAzyme field, ${ }^{24,46}$ possibly due to the close to neutral $\mathrm{p} K_{\mathrm{a}}$ value of the $\mathrm{Pb}^{2+}$ bound water, ${ }^{47}$ making it ideal for activating the 2 '-OH nucleophile. Even for $\mathrm{Pb}^{2+}$, the rate of cleavage $\left(\sim 0.0013 \mathrm{~min}^{-1}\right.$ with $\left.100 \mu \mathrm{M} \mathrm{Pb}^{2+}\right)$ under the same metal concentration is still $>3000$-fold slower compared to that for $\mathrm{Ag}^{+}\left(0.41 \mathrm{~min}^{-1}\right.$ with $\left.10 \mu \mathrm{M} \mathrm{Ag}^{+}\right)$. For the other metals, the selectivity of $\mathrm{Ag} 10 \mathrm{c}$ for $\mathrm{Ag}^{+}$is even higher, making it an excellent probe for $\mathrm{Ag}^{+}$ sensing.

A silver biosensor. From the studies above, it is clear that $\mathrm{Ag} 10 \mathrm{c}$ is highly specific for $\mathrm{Ag}^{+}$with fast catalytic rate, allowing building a biosensor for $\mathrm{Ag}^{+}$. Among the various signaling strategies, we herein employed a catalytic beacon method for its high sensitivity. ${ }^{6,46}$ We labeled the $3^{\prime}$-end of the enzyme strand with a Black Hole Quencher (named Ag10c-Q in Table S1), which upon hybridization, quenches the fluorescence of the FAM fluorophore labeled on the 5'-end of the 
substrate (5'-FAM-Sub). In the presence of $\mathrm{Ag}^{+}$, cleavage of the substrate rescues the fluorescence after releasing the cleaved fragment (Figure 6A). The structure of the sensor DNAzyme complex is shown in Figure S2.

We executed this experiment with increasing concentration of $\mathrm{Ag}^{+}$by monitoring the signaling kinetics at pH 7.5, $50 \mathrm{mM}$ MOPS, $200 \mathrm{mM} \mathrm{NaNO}_{3}$ (Figure 6B). In the absence of $\mathrm{Ag}^{+}$, the background was quite stable, indicating a stable DNAzyme complex. The rate of fluorescence enhancement rapidly increased with higher $\mathrm{Ag}^{+}$concentration. We quantified the initial rates in Figure $6 \mathrm{C}$, and the dynamic range reached $\sim 400 \mathrm{nM} \mathrm{Ag}^{+}$. The low $\mathrm{Ag}^{+}$concentration region is shown in the inset of Figure 6C, and we calculated a limit of detection (LOD) of $24.9 \mathrm{nM} \mathrm{Ag}^{+}$ based on $3 \sigma /$ slope ( $\sigma$ is the standard deviation of the background signal). This is 37 -fold lower than the maximum permissible contamination level of silver in water i.e. $0.1 \mathrm{mg} / \mathrm{L}$ or $930 \mathrm{nM}$ defined by the World Health Organization.

To test for selectivity, the sensor was then challenged with various monovalent, divalent and trivalent cations. The signal remained at the background level with most ions, while a few caused fluorescence quenching. The only one (except $\mathrm{Ag}^{+}$) with fluorescence increase was $\mathrm{Hg}^{2+}$, both a $1 \mu \mathrm{M}$ and at $100 \mu \mathrm{M}$ concentrations. Since the gel-based assay with similar concentrations of $\mathrm{Hg}^{2+}$ did not produce any cleavage (Figure 5B), we speculated that the fluorescence increase was from $\mathrm{Hg}^{2+}$-induced DNA misfolding. $\mathrm{Hg}^{2+}$ has strong affinity with DNA pyrimidine bases, which may fold the FAM label away from the quencher, thus enhancing the fluorescence. If this hypothesis is true, such a rise in fluorescence should be reversible if the $\mathrm{Hg}^{2+}$ ions are made unavailable. To test it, we initiated the rise in fluorescence with $1 \mu \mathrm{M} \mathrm{Hg}^{2+}$ or $400 \mathrm{nM} \mathrm{Ag}^{+}$. $\mathrm{Upon}$ signal stabilization, $10 \mu \mathrm{M} \mathrm{NaI}$ was added to both reactions (Figure 6E). Indeed, in the $\mathrm{Hg}^{2+}$ reaction, the signal went back to the background level due to $\mathrm{HgI}_{2}$ formation, while no change was 
seen in the $\mathrm{Ag}^{+}$reaction upon formation of $\mathrm{AgI}$, proving that the sensor was irreversibly cleaved by silver ions. It might be possible to eliminate the signal from $\mathrm{Hg}^{2+}$ by using other designs, such as gold nanoparticle based colorimetric sensors, ${ }^{48}$ or using more stably folded DNAzyme secondary structures. ${ }^{49}$ While $\mathrm{Pb}^{2+}$ showed a slight cleavage in gel-based assay, its rate is $>3000$ fold slower than $\mathrm{Ag}^{+}$, and $\mathrm{Pb}^{2+}$ is a strong fluorescence quencher at high concentrations. These factors may explain the lack of $\mathrm{Pb}^{2+}$ response in this rate-based signaling method.

Further, we wanted to study if this sensor works in real word water samples. For this, our sensor was tested in Lake Huron water with 50 mM MOPS buffer (pH 7.5, 90\% of lake water in the final reaction, Figure $6 \mathrm{~F}$ ). The response was quite similar to that obtained in clean buffers, and a LOD of $21.8 \mathrm{nM}$ was calculated (Figure S3). Therefore, the lake water matrix did not interfere with the detection. The Great Lake's water often contains below $1 \mathrm{mM} \mathrm{Cl}^{-50}$ and therefore it is understandable that the sensitivity of our sensor was not affect.
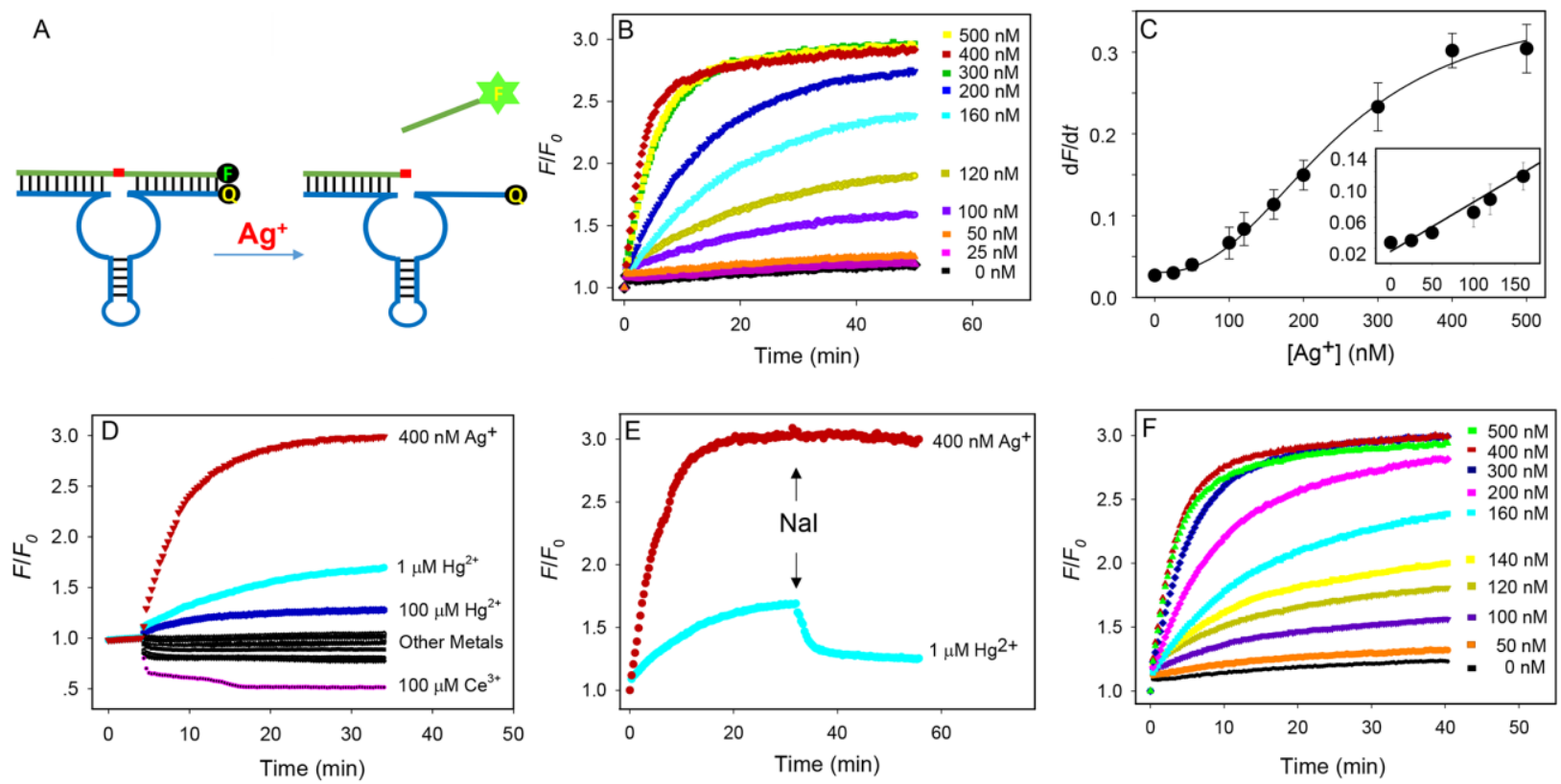

Figure 6. (A) Schematic representation of the $\mathrm{Ag}^{+}$DNAzyme beacon design. (B) Sensor signaling kinetics at various concentrations of $\mathrm{Ag}^{+}$. (C) Quantification of $\mathrm{Ag}^{+}$based on the initial rate of 
fluorescence enhancement. Inset: the low $\mathrm{Ag}^{+}$concentration region fitted with a linear response. Sensor signaling kinetics with (D) various metal ions: 1 and $100 \mathrm{mM} \mathrm{K}^{+}, \mathrm{Li}^{+}, \mathrm{Rb}^{+}, \mathrm{Na}^{+}, \mathrm{Cs}^{+} ; 1$ and $10 \mathrm{mM} \mathrm{Ca}^{2+}, \mathrm{Mg}^{2+}, 1$ and $100 \mu \mathrm{M} \mathrm{Mn}^{2+}, \mathrm{Fe}^{2+}, \mathrm{Cu}^{2+}, \mathrm{Zn}^{2+}, \mathrm{Ni}^{2+}, \mathrm{Co}^{2+}, \mathrm{Cd}^{2+}, \mathrm{Pb}^{2+}, \mathrm{Sr}^{2+}, \mathrm{Ce}^{3+}$ and

$\mathrm{Fe}^{3+}$. (E) Sensor response to $400 \mathrm{nM} \mathrm{Ag}^{+}$and $1 \mu \mathrm{M} \mathrm{Hg}^{2+}$ where the black arrows indicate the time of addition of $10 \mu \mathrm{M} \mathrm{NaI}$. The fluorescence dropping in the $\mathrm{Hg}^{2+}$ reaction indicates its signaling was not due to cleavage. All the reactions were performed in $50 \mathrm{mM}$ MOPS, pH 7.5 with $200 \mathrm{mM}$ $\mathrm{NaNO}_{3}$. The final sensor concentration was $50 \mathrm{nM}$. (F) Detecting spiked $\mathrm{Ag}^{+}$in Lake Huron water.

\section{Conclusions}

In conclusion, we reported the first $\mathrm{Ag}^{+}$- specific RNA-cleaving DNAzyme, which was evolved in course of an in vitro selection effort using silver as the intended metal cofactor. This enzyme named Ag10c, shows high selectivity for silver over other metal ions and a fast catalytic rate of $0.41 \mathrm{~min}^{-1}$ at $\mathrm{pH} 7.5$ and $200 \mathrm{mM} \mathrm{NaNO}_{3}$ with just $10 \mu \mathrm{M} \mathrm{Ag}^{+}$. This study highlights the possibility of using monovalent transition metal ions as a cofactor for DNAzyme catalysis. We have also demonstrated the use of this DNAzyme for selectively sensing low concentrations of $\mathrm{Ag}^{+}$ions, with the LOD of the sensor being $24.9 \mathrm{nM}$, which is far below the permissible limit of silver in water. Taken together, this enzyme is not only a useful analytical probe for silver, but also gives a platform to study the role of monovalent ions in DNAzyme catalysis.

\section{Supporting Information Available:}

DNA sequences, DNAzyme secondary structures, and detection in Lake Huron water. This information is available free of charge via the Internet at http://pubs.acs.org/. 


\section{Acknowledgement}

This work is supported by the Natural Sciences and Engineering Research Council of Canada (NSERC) Strategic Project Grant: STPGP-447472-2013.

\section{References}

(1) Drake, P. L.; Hazelwood, K. J. Ann. Occup. Hyg. 2005, 49, 575-585.

(2) Ratte, H. T. Environ. Toxicol. Chem. 1999, 18, 89-108.

(3) Coskun, A.; Akkaya, E. U. J. Am. Chem. Soc. 2005, 127, 10464-10465.

(4) Chatterjee, A.; Santra, M.; Won, N.; Kim, S.; Kim, J. K.; Bin Kim, S.; Ahn, K. H. J. Am. Chem. Soc. 2009, 131, 2040-2041.

(5) Zhang, X.-B.; Kong, R.-M.; Lu, Y. Annu. Rev. Anal. Chem. 2011, 4, 105-128.

(6) Liu, J.; Cao, Z.; Lu, Y. Chem. Rev. 2009, 109, 1948-1998.

(7) Schlosser, K.; Li, Y. F. Chem. Biol. 2009, 16, 311-322.

(8) Song, S. P.; Qin, Y.; He, Y.; Huang, Q.; Fan, C. H.; Chen, H. Y. Chem. Soc. Rev. 2010, 39, 4234-4243.

(9) Wang, H.; Yang, R. H.; Yang, L.; Tan, W. H. ACS Nano 2009, 3, 2451-2460.

(10) Katz, E.; Willner, I. Angew. Chem., Int. Ed. 2004, 43, 6042-6108.

(11) Lu, Y. Inorg. Chem. 2006, 45, 9930-9940.

(12) Liu, J. Can. J. Chem. 2015, 93, 273-278.

(13) Joyce, G. F. Ann. Rev. Biochem. 2004, 73, 791-836.

(14) Lu, Y. Chem. Eur. J. 2002, 8, 4588-4596.

(15) Breaker, R. R.; Joyce, G. F. Chem. Biol. 1994, 1, 223-229. 
(16) Li, J.; Zheng, W.; Kwon, A. H.; Lu, Y. Nucleic Acids Res. 2000, 28, 481-488.

(17) Carmi, N.; Balkhi, H. R.; Breaker, R. R. Proc. Natl. Acad. Sci. U.S.A. 1998, 95, 22332237.

(18) Cuenoud, B.; Szostak, J. W. Nature 1995, 375, 611-614.

(19) Liu, J.; Brown, A. K.; Meng, X.; Cropek, D. M.; Istok, J. D.; Watson, D. B.; Lu, Y. Proc. Natl. Acad. Sci. U.S.A. 2007, 104, 2056-2061.

(20) Huang, P.-J. J.; Liu, J. Nucleic Acids Res. 2015, 43, 6125-6133.

(21) Hollenstein, M.; Hipolito, C.; Lam, C.; Dietrich, D.; Perrin, D. M. Angew. Chem., Int. Ed. 2008, 47, 4346 - 4350.

(22) Huang, P.-J. J.; Vazin, M.; Matuszek, Ż.; Liu, J. Nucleic Acids Res. 2015, 43, 461-469.

(23) Huang, P.-J. J.; Vazin, M.; Liu, J. Anal. Chem. 2014, 86, 9993-9999.

(24) Huang, P.-J. J.; Lin, J.; Cao, J.; Vazin, M.; Liu, J. Anal. Chem. 2014, 86, 1816-1821.

(25) Roth, A.; Breaker, R. R. Proc. Natl. Acad. Sci. U.S.A. 1998, 95, 6027-6031.

(26) Geyer, C. R.; Sen, D. Chem. Biol. 1997, 4, 579-593.

(27) Torabi, S.-F.; Wu, P.; McGhee, C. E.; Chen, L.; Hwang, K.; Zheng, N.; Cheng, J.; Lu, Y. Proc. Natl. Acad. Sci. U.S.A. 2015, 112, 5903-5908.

(28) Zhou, W.; Zhang, Y.; Huang, P.-J. J.; Ding, J.; Liu, J. Nucleic Acids Res. 2016, 44, $354-$ 363.

(29) Torabi, S.-F.; Lu, Y. J. Mol. Evol. 2015, 81, 225-234.

(30) Zhou, W.; Saran, R.; Chen, Q.; Ding, J.; Liu, J. ChemBioChem 2016, 17, 159-163.

(31) Ono, A.; Cao, S.; Togashi, H.; Tashiro, M.; Fujimoto, T.; Machinami, T.; Oda, S.; Miyake, Y.; Okamoto, I.; Tanaka, Y. Chem. Commun. 2008, 4825-4827.

(32) Urata, H.; Yamaguchi, E.; Nakamura, Y.; Wada, S.-I. Chem. Commun. 2011, 47, 941943.

(33) Freeman, R.; Finder, T.; Willner, I. Angew. Chem., Int. Ed. 2009, 48, 7818-7821.

(34) Wen, Y. Q.; Xing, F. F.; He, S. J.; Song, S. P.; Wang, L. H.; Long, Y. T.; Li, D.; Fan, C. H. Chem. Commun. 2010, 46, 2596-2598. 
(35) Li, T.; Shi, L.; Wang, E.; Dong, S. Chem. Eur. J. 2009, 15, 3347-3350.

(36) Su, Y.-T.; Lan, G.-Y.; Chen, W.-Y.; Chang, H.-T. Anal. Chem. 2010, 82, 8566-8572.

(37) Richards, C. I.; Choi, S.; Hsiang, J.-C.; Antoku, Y.; Vosch, T.; Bongiorno, A.; Tzeng, Y.L.; Dickson, R. M. J. Am. Chem. Soc. 2008, 130, 5038-5039.

(38) Li, Y.; Breaker, R. R. J. Am. Chem. Soc. 1999, 121, 5364-5372.

(39) Ward, W. L.; Plakos, K.; DeRose, V. J. Chem. Rev. 2014, 114, 4318-4342.

(40) Sigel, R. K. O.; Pyle, A. M. Chem. Rev. 2007, 107, 97-113.

(41) Zuker, M. Nucleic Acids Res. 2003, 31, 3406-3415.

(42) Vazin, M.; Huang, P.-J. J.; Matuszek, Ż.; Liu, J. Biochemistry 2015, 54, 6132-6138.

(43) Liu, J.; Lu, Y. Angew. Chem., Int. Ed. 2007, 46, 7587-7590.

(44) Dahm, S. C.; Derrick, W. B.; Uhlenbeck, O. C. Biochemistry 1993, 32, 13040-13045.

(45) Sauls, F. C. J. Chem. Edu. 2013, 90, 1212-1214.

(46) Li, J.; Lu, Y. J. Am. Chem. Soc. 2000, 122, 10466-10467.

(47) Burgess, J. Metal ions in solution; Ellis Horwood Ltd. : Chichester, 1978.

(48) Liu, J. W.; Lu, Y. J. Am. Chem. Soc. 2003, 125, 6642-6643.

(49) Li, H.; Zhang, Q.; Cai, Y.; Kong, D.-M.; Shen, H.-X. Biosens. Bioelectron. 2012, 34, 159-164.

(50) Dove, A. Aquat. Ecosyst. Health. 2009, 12, 281-295. 